
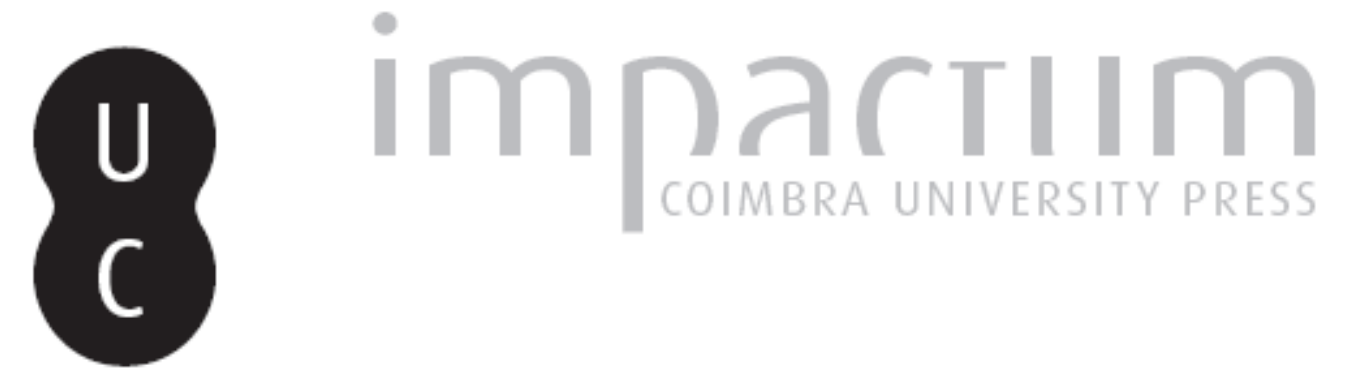

\title{
A cidadania infantil na Primeira República e a tutoria da infância: a criação da Tutoria de Coimbra e do refúgio anexo
}

Autor(es): $\quad$ Tomé, Maria Rosa

Publicado por: Centro de História da Sociedade e da Cultura

URL persistente:

URI:http://hdl.handle.net/10316.2/39532

DOI:

DOI:http://dx.doi.org/10.14195/1645-2259_10-2_6

Accessed : $\quad$ 26-Apr-2023 02:00:01

A navegação consulta e descarregamento dos títulos inseridos nas Bibliotecas Digitais UC Digitalis, UC Pombalina e UC Impactum, pressupõem a aceitação plena e sem reservas dos Termos e Condições de Uso destas Bibliotecas Digitais, disponíveis em https://digitalis.uc.pt/pt-pt/termos.

Conforme exposto nos referidos Termos e Condições de Uso, o descarregamento de títulos de acesso restrito requer uma licença válida de autorização devendo o utilizador aceder ao(s) documento(s) a partir de um endereço de IP da instituição detentora da supramencionada licença.

Ao utilizador é apenas permitido o descarregamento para uso pessoal, pelo que o emprego do(s) título(s) descarregado(s) para outro fim, designadamente comercial, carece de autorização do respetivo autor ou editor da obra.

Na medida em que todas as obras da UC Digitalis se encontram protegidas pelo Código do Direito de Autor e Direitos Conexos e demais legislação aplicável, toda a cópia, parcial ou total, deste documento, nos casos em que é legalmente admitida, deverá conter ou fazer-se acompanhar por este aviso.

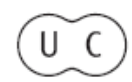




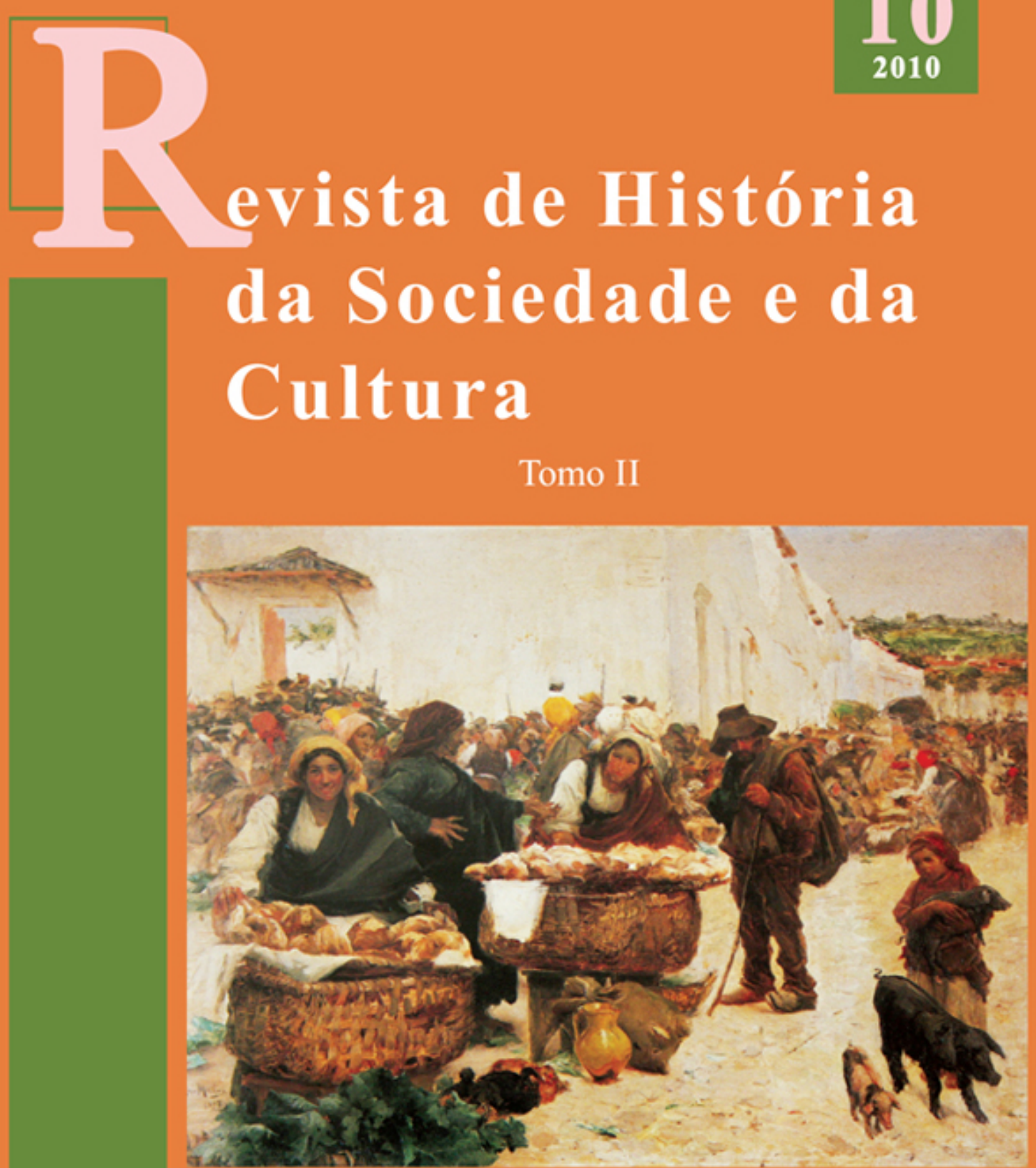

Centro de História da Sociedade e da Cultura Universidade de Coimbra

Coimbra 


\title{
A cidadania infantil na Primeira República e a tutoria da infância. A criação da Tutoria de Coimbra e do refúgio anexo*
}

\author{
Maria Rosa Tomé \\ Doutoranda na Universidade de Coimbra \\ Assistente no Instituto Superior Miguel Torga em Coimbra \\ rosa tome@hotmail.com \\ Texto recebido em/ Text submitted on: 30/01/2010 \\ Texto aprovado em/ Text approved on: 07/05/2010
}

\section{Resumo/Abstract:}

Sob forte influência do debate internacional e com apoio político dos republicanos, a Lei de Protecção à Infância (LPI) de 1911, constitui uma referência para o avanço da cidadania infantil em Portugal. A criação da Tutoria da Infância e da Federação Nacional dos Amigos e Defensores das Crianças prometiam a aplicação de medidas preventivas e profiláticas para garantir a defesa dos direitos da criança. Contudo, era preciso um investimento maior e mais diversificado, acima de tudo, para enfrentar os problemas estruturais da sociedade portuguesa. Nos grandes centros urbanos as dificuldades das crianças e as suas famílias eram crescentes. Em Coimbra, a pobreza atingia também algumas das instituições de apoio social às crianças. A criação da Tutoria da Infância e do Refúgio anexo, foi então necessária à obra da assistência (ou tão só mais uma obra de assistência à criança em Coimbra).

Under the strong influence of the international debate and with the political support of the Republicans, the Childhood Protection Law (Lei de Protecção à Infância - LPI) of 1911 is a reference of the progress of infant citizenship in Portugal. The formation of the Tutoria da Infância and the Federação Nacional dos Amigos e Defensores das Crianças promised the implementation of preventive and prophylactic measures for safeguarding children's rights. However, there was the need for more and diversified investment, particularly to respond to the structural problems of Portuguese society. In large urban centres, children and their families faced growing constraints. In Coimbra, poverty was also inflicted on institutions of children's social welfare. The formation of the Tutoria da Infância and its shelter provided essential support (or was one more institution providing child care in Coimbra).

Palavras chave/Keywords:

Protecção social e judicial; Cidadania infantil.

Social and legal protection; Infant citizenship.

* O estudo aqui apresentado insere-se num projecto ainda em curso sobre a política social dirigida à infância em Portugal e que constitui a investigação para doutoramento, na especialidade de História Contemporânea, na Faculdade de Letras da Universidade de Coimbra. 


\section{Modernidade e cidadania infantil}

No século XIX a questão da infância tornou-se uma especificidade da questão social. A criança ganhou estatuto e mérito para se tornar objecto de atenção e de controlo em vários domínios da vida civil, social, laboral, escolar e penal. No século XX, foi o primeiro grupo a merecer uma declaração específica no quadro dos Direitos do Homem. A Declaração dos Direitos da Criança, conhecida como Declaração de Genebra, foi aprovada na International Save the Children Union, em 1923, e adoptada por unanimidade pela Assembleia da Sociedade das Nações (V sessão), em Genebra, em 1924. Ainda por esta década, diferentes países europeus legislaram políticas de protecção judicial específicas, para defender os seus direitos e interesses.

Os problemas da/com a criança e do/com o jovem, inerentes ao processo de crescente industrialização e urbanização, bem como os mecanismos de protecção social que se iam desenvolvendo em cada país, foram sistematicamente debatidos nos congressos internacionais, de tal forma que podemos considerar que uma "internacional da infância"1 socializou os conceitos e as respostas aos problemas, abrindo caminho à "internacionalização" de tendências sobre a definição das idades mínimas para o trabalho ${ }^{2}$, sobre a escolaridade obrigatória ${ }^{3}$, a repressão contra a

1 Expressão usada por referência à internacionalização das medidas de protecção social e judiciária, difundidas pelos congressos internacionais de protecção à infância e penitenciários. Cf. DUPONT-BOUCHAT, M. S. and PIERRE, E. (ed.) - Enfance et justice au XIX siècle. Paris: PUF, 2001, cap. 6.

2 Ver a regulamentação, primeiro em Inglaterra, na Prússia, em França, etc. Em Portugal o Código Civil de 1867 impunha o limite máximo de 9 h de trabalho diário aos menores de 14 anos. Cf. LOPES, Maria Antónia - Crianças e Jovens em risco no século XVIII e XIX. O caso português no contexto europeu. Revista de História da Sociedade e da Cultura. 2 (2002) 155-184. A OIT criada em 1919 deu início à organização de princípios internacionais de organização do trabalho, tais como a supressão do trabalho das crianças e a limitação do dos jovens, a fim de lhes permitir a sua educação. Em 1931, 53 países integravam esta organização, apesar de haver no seu seio diferentes ritmos de adesão às suas orientações. Cf. CASTIGLIONI G. E. di Palma - Conferência apresentada à X Sessão da Associação, Internacional de Protecção à Infância. Miscelânea. Lisboa, 1931.

3 De uma forma geral por todo o lado, o Liberalismo lançou as bases para a universalização da instrução e para o combate ao analfabetismo. Em Portugal, a República criou 50 novas escolas de primeiras letras e com elas baixou o analfabetismo. Cf. TOMÉ, Maria Rosa - A criança e a delinquência juvenil na Primeira República. Lisboa: CPIHTS, 
mendicidade, a promoção das condições de vida pela luta contra a pobreza, contra a doença e mortalidade infantil, entre outras. Para o final do século XIX e princípios do século XX, intensificaram-se as trocas de ideias sobre a sua protecção, pelo controlo judiciário dos interesses e direitos dos jovens de menor idade, pela criação de tribunais tutelares, à semelhança dos tribunais americanos, que se difundiram pela Europa particularmente pelos anos 20 do século XX e que ficaram conhecidos como tutorias/tribunais de Menores.

Entre a segunda metade do século XIX e as primeiras duas décadas do século $\mathrm{XX}$, as respostas sociais americanas e europeias vieram por iniciativa de personalidades e de movimentos sociais, fortemente apoiados pelas Igrejas $^{4}$ e pelos governos ${ }^{5}$. De assunto privado, familiar, a criança passou a assunto de Estado, com garantias registadas nos códigos, civil e penal. Do ponto de vista do direito civil, o século XIX acrescentou à noção de menoridade e da tutela obrigatória a definição dos limites ao exercício do seu poder. Do ponto de vista penal, o século XX definiu a inimputabilidade pela idade, marcando o desenvolvimento de um sistema de protecção especial para as crianças e jovens que não estivessem devidamente inseridas nas instituições sociais que o sistema económico e social definiu

2003, p. 72. Em 1911 75,1\% da população portuguesa era analfabeta. Entre 1911 e 1930, o analfabetismo cresceu em números absolutos em cerca de 150.000, mas em termos relativos baixou para $67,8 \%$. O analfabetismo feminino era substancialmente superior. Cf. CARVAlHO, Rómulo - História do ensino em Portugal, desde a fundação da nacionalidade até ao regime de Salazar-Caetano. Lisboa: Fundação Calouste Gulbenkian, 1986, p. 726. Os países do norte da Europa fizeram disto um combate, de tal maneira que na Finlândia da década de 1930 o analfabetismo estava praticamente extinto. Cf. TOMÉ, Maria Rosa - A criança e a delinquência ... cit, p. 74.

$4 \mathrm{Na}$ Europa católica, o movimento de laicização e a secularização que influenciou grande parte deste período expulsou a Igreja deste processo. Contudo, as dificuldades de recrutamento de pessoal especializado para o funcionamento do sistema e o facto de haver experiência acumulada pelas Ordens Religiosas em matéria de educação, permitiu que estas, muitas vezes, fossem a "solução" adoptada, principalmente para se ocuparem das raparigas. Neste sentido ver o papel das Irmãs do Bom Pastor de Angers e as Irmãs da Caridade de Gand em DUPONT-BOUCHAT, M S and PIERRE, E - Enfance et justice..., cit., p. 86-89.

5 Por todos os países se verifica que alguns dos filantropos ocupavam cargos executivos, eram ministros, directores das prisões, pertenciam às elites influentes, etc. Sobre a situação no EUA, cf. PLATT, A. - Los salvadores del ninho. A invenção de la delinquência. México; Argentina: Siglo XXI, $4^{\mathrm{a}}$ ed., p. 70-78. Nos países francófonos, cf. DUPONT-BOUCHAT, M S and PIERRE, E - Enfance et justice..., cit., p. 52-61 Em Portugal, cf. TOMÉ, Maria Rosa - A criança e a delinquência...cit., p. 90. 
como fundamentais para o seu desenvolvimento adequado, bem como ao cumprimento das expectativas que a modernidade abriu para todos.

Segundo Dominique de Fraene ${ }^{6}$, quatro "forças produtivas" interagiram no sentido da criação de um sistema de protecção à infância, precursor da definição de um quadro judiciário para o estabelecimento de um regime especial para menores. A saber: o desenvolvimento de uma forte e sustentada atitude crítica face aos efeitos do sistema penal sobre os menores; a compreensão de que as crianças podiam engrossar o reservatório de mão-de-obra disponível e adaptá-lo às necessidades da indústria; a sensibilidade humanista de alguns sectores da burguesia, críticos da aplicação de um regime meramente retributivo às crianças e jovens infractoras à lei penal; e o nascimento de uma racionalidade científica, essencialmente clínica, para tratar a inadaptação social, de forma a controlar a sua perigosidade.

\section{A Assistência à infância e a criação dos Tribunais de Menores}

Em Portugal, particularmente com a Regeneração, assistimos ao desenvolvimento de uma atenção especial à questão da infância como estratégia de regeneração da nação. A sua protecção, controlo e educação foram entendidas como um investimento para o desenvolvimento e para a riqueza do país. Assim, a criança tornou-se um alvo de diferentes áreas da ciência e de políticas sociais e judiciais. A monarquia liberal portuguesa do século XIX, atenta à questão social, obrigou o Estado a promover, regulamentar e fiscalizar a beneficência, fomentando a criação de instituições que, oriundas de subscrições privadas, foram fortemente apoiadas pelos governos. Às misericórdias, herança que permanecia indispensável pelo papel que desempenhavam no socorro aos pobres e doentes, juntaram-se os asilos da mendicidade e da infância desvalida, as associações de socorros mútuos, as creches, os albergues nocturnos, os dispensários, os lactários e as cozinhas económicas. Assim, a prevenção da doença, a repressão

6 FRAENE, Dominique de - A Reforma da Justiça dos Menores. Entre Compromissos Pragmáticos e Aporias Crónicas. Infância e Juventude. 99.3 (1999) 10-11. 
da mendicidade e do crime, o socorro à invalidez e à infância foram preocupações e linhas centrais de intervenção nos governos liberais?

A atenção dirigida a estes grupos desenvolveu-se no seio de pensamentos conflituantes entre as velhas ideias conservadoras e as novas ideias liberais, entre a influência conservadora da Igreja e a vaga reformista do cientismo em desenvolvimento. Identificamos três correntes que, grosso modo, persistiram nas primeiras décadas do século XX. A primeira diz respeito à influência da Igreja na beneficência. Os ideais da caridade cristã tiveram primazia, por vezes articulados de forma ecléctica com o conceito emergente de assistência por direito ${ }^{8}$. Algumas instituições, eram apoiados por ordens religiosas, como por exemplo o Dispensário Rainha D. Amélia, cuja enfermagem foi entregue às irmãs dominicanas até à implantação da República, altura em que foi encerrado. Quando reabriu, o serviço de enfermagem profissionalizou e laicizou? 9

Na Primeira República foi declarado por Afonso Costa, responsável pela lei da separação, que os bens da Igreja seriam entregues à protecção à infância ${ }^{10}$. A direcção das obras nascidas com o republicanismo tiveram uma orientação laica até que o Estado Novo permitiu, primeiro, reintroduzir o catolicismo no processo educativo dos jovens internos e, depois de assinada a concordata, a passagem da direcção e do modelo educativo de algumas instituições para as ordens religiosas ${ }^{11}$.

7 LOPES, Maria Antónia e PAIVA, José Pedro - Introdução in LOPES, Maria Antónia e PAIVA, José Pedro (dir.) - Portugaliae Monumenta Misericordiarum 8. Tradição e modernidade: o período da monarquia constitucional (1834-1910). Lisboa: União das Misericórdias Portuguesas, 2010, p. 7-30.

8 LOPES, Maria Antónia e PAIVA, José Pedro - Introdução, cit.

9 MARTINS, Alcina - Génese, emergência e institucionalização do serviço social português. Lisboa: Fundação Calouste Gulbenkian e FCT, 1999, p. 58-60.

${ }^{10}$ Discurso de Afonso Costa à Câmara de Deputados in Diário da Câmara de Deputados de 2 de Agosto de 1911, 36 a sessão e artigo 104 ${ }^{\circ}, 2^{\circ}$ da Lei da Separação da Igreja e do Estado, de 20 de Abril de 1911. No Decreto-Lei 10:767 de 15 de Maio de 1925, artigo 130º, pode ler-se "Os bens das extintas congregações religiosas que estão ou vierem a ficar na livre disposição do Estado, constituem um património confiado à guarda e administração da Federação Nacional das Instituições de Protecção à Infância". A secção administrativa da Federação designava-se "Comissão Jurisdicional dos Bens das Extintas Congregações Religiosas" (artigo $131^{\circ}$ ).

${ }^{11}$ A Congregação da Nossa Senhora da Caridade do Bom Pastor de Angers assumiu a partir de 1944 a direcção do Reformatório Feminino de Viseu, criado em 1928. Em 1962 foi firmado um protocolo entre a Direcção-Geral dos Serviços Jurisdicionais de Menores 
A segunda diz respeito ao movimento da medicina social e do higienismo. Segundo Foucault ${ }^{12}$, a construção histórica do que chamou medicina social e urbana, que se desenvolveu particularmente a partir da Alemanha, França e Inglaterra, com a introdução da importância política da medicalização, da investigação médica e do desenvolvimento das instituições de saúde, deu origem, a partir do século XVIII, ao nascimento de uma economia da saúde e de uma medicina social, com o fundamento de construir uma certa tecnologia do corpo social e uma boa relação entre o organismo e o meio. Por um lado, o reconhecimento político, económico e social do corpo como força de trabalho, fez da medicina uma "estratégia biopolítica"13 e, por outro, a importância reconhecida às condições de vida e bem-estar, fez com que, na prática, introduzisse um corpus físico-químico para controlo das coisas do ambiente. Esta biotecnologia permitia então um controlo disciplinar sobre as pessoas e um processo de regulação estatal sobre a população ${ }^{14}$.

Assim, e depois da definição de salubridade do espaço urbano e da criação de mecanismos de atenção médica à pobreza muitas instituições nasceram, conferindo ao panorama da filantropia uma nova roupagem especializada, atenta ao problema da insalubridade urbana, da falta de água potável, das epidemias, da fome, da mortalidade infantil e tantos outros problemas quer exigiram a tomada de medidas públicas profiláticas e eugénicas, que contaram com a forte contribuição dos médicos ${ }^{15}$.

(DGSJM), Eurico Simões Serra e a Irmã Maria do Precioso Sangue, superiora provincial da Congregação, reforçando, ao abrigo do artigo $2^{\circ}$ do Decreto-Lei n. ${ }^{\circ} 33262$ de 24 de Novembro de 1943, a cooperação nos termos do acordo. Passaram para sua direcção o Reformatório de Viseu, que passou a designar-se Instituto de São José e o Instituto Corpus Christi em Vila Nova de Gaia. Em 1961 foi revisto o acordo elaborado em 1951 entre a DGSJM e a Província Portuguesa da Sociedade Salesiana, assinado por Eurico Simões Serra e pelo padre Armando da Costa Monteiro, atribuindo-lhe a direcção da Colónia Correccional de Izeda, que passou a designar-se Escola Profissional de Santo António. Cf. BANDEIRA, Filomena - O reformatório feminino de Viseu: São José do Bom Pastor. A reestruturação da rede em meados do século XX in Arquitectura de serviços públicos em Portugal: os internatos na justiça de menores 1871-1978. Lisboa: DGRS e IHRU, p. 205. Infância e Juventude 28 (1961).

${ }^{12}$ FOUCAULT, Michel - Estrategias de poder. Obras essenciales, vol II. Barcelona: Paidós, 1999, p. 363-366.

${ }^{13}$ FOUCAULT, Michel - Estrategias... p. 366.

${ }^{14}$ FOUCAULT, Michel - É preciso defender a sociedade. Lisboa: Livros do Brasil, p. $255-267$.

${ }^{15}$ MARTINS, Alcina - Génese, emergência ...cit., p. 51 e ss. 
Uma terceira discussão, alimentada pela filosofia jurídica, vem desacreditar a tese do livre arbítrio em favor do positivismo e defender a implementação de medidas de prevenção pela vigilância social dos indivíduos, como estratégia central de defesa social e de controlo dos problemas que pudessem causar dano à vida social. Esta perspectiva centra a atenção nos indivíduos e no seu controlo. Particularmente no domínio da criminologia desviou o discurso do crime para o criminoso, do acto para o actor. Em matéria penal, a sanção à medida do dano causado ${ }^{16}$ foi substituída pela sanção com a medida necessária à recuperação social do indivíduo, para a defesa da sociedade, criando-se, em alternativa à pena de prisão, uma forma de vigilância social pelo sistema de probation e pela liberdade condicional, ou, em caso de reconhecida perigosidade, a sentença indeterminada.

É no âmbito do desenvolvimento destas ideias que a preocupação com os jovens de menor idade se tornou alvo de uma atenção particular pelo mundo fora. O problema da infância pobre, maltratada, vadia, mendiga, anormal, indisciplinada e delinquente era uma afronta à ordem social e corria pelo mundo desde o século XIX, por via da tomada de consciência, quer social quer judicial, que a defesa social como princípio de justiça exigia medidas "prevenção" 17 à inadaptação social, pela conjugação de medidas de assistência com medidas de prevenção criminal. Esta preocupação, é bem evidente nos congressos internacionais sobre a protecção da infância e nos congressos penitenciários internacionais dos finais do século XIX e princípios do século XX (1886-1921). Sendo já voz corrente a necessidade

${ }^{16}$ A justa medida da pena em função do dano causado era apanágio das teses clássicas do crime. A criminologia positivista exigia o conhecimento do sujeito, da sua condição e motivações para o crime. Assim era possível enquadrá-lo numa tipologia indicativa do seu grau de perigosidade. Uma equipa de peritos tinha como função determinar "o tipo", informar o juiz, para que a medida fosse adequada ao sujeito, à sua recuperação social e preventiva em relação à reincidência. Sobre as teses do livre arbítrio cf. BECCARIA, Cesare - Dos Delitos e das Penas. Lisboa: Edição da Fundação Calouste Gulbenkien, 1998. Sobre a criminologia nova e seus procedimentos. COSTA, Afonso - Comentário ao Código Penal Português. Escolas e princípios de criminologia moderna. Coimbra, 1895 e Os Peritos no processo penal - Legislação portuguesa, crítica, reformas. Coimbra, 1895.

${ }^{17}$ É de notar o carácter restritivo do conceito à ideia de defesa social, nos princípios do século XX e, portanto, à prevenção dos efeitos da inadaptação social. Não obstante o desenvolvimento do discurso dos direitos sociais que se foi acentuando a partir de meados do século XX, o conceito inscrito na legislação tinha maior valor de controlo e disciplina do que de luta contra a exclusão social. 
de separar as crianças e os jovens dos adultos em cumprimento de pena de prisão, o Congresso Internacional de Protecção à Infância de 1886, realizado em Paris, já divulgava os relatórios dos diferentes países sobre os recursos institucionais para as crianças abandonadas e para os jovens infractores ${ }^{18}$. A partir de então discute-se: i) a definição da prevenção como forma de aplicação do princípio de defesa social à criança, a formação do pessoal de vigilância, entre outros, no Congresso Penitenciário de Estocolmo, em $1878^{19}$; ii) a categorização da infância, nos Congressos de São Petersburgo e de Antuérpia em $1890^{20}$; iii) a substituição da sanção penal por medidas de protecção, de prevenção e de regeneração, bem como a criação de um tribunal para jovens a partir dos 16 anos e a definição do papel dos mecanismos de vigilância social e apoio à reinserção social dos jovens saídos dos internatos (o patronato), no Congresso de Washington em $1910^{21}$. Em 1911, no Congresso Internacional para os Tribunais da Infância ${ }^{22}$, difundiu-se a discussão sobre a criação do tribunal de menores, sua composição e funcionamento, as regras próprias de processo, mais simplificadas e personalizadas, as medidas de protecção e de prevenção criminal, em vez de medidas sancionatórias, os limites de idade das crianças ou jovens que deviam ser julgados em tribunal de menores. Foram ainda debatidos e aprofundados nos congressos temas como a relação entre os tribunais e as famílias das crianças e jovens, a questão das crianças "anormais", os métodos de observação e profilaxia a desenvolver, a especialização do pessoal, entre outras, bem como foram permitidas a troca de ideias e de experiências entre os países participantes.

${ }^{18}$ Cf. BONJEAN, M. M. - Congrès International de la Protection de l'Enfance. Paris: A Durand et Pedone-Lauriel editeurs, Livraire de la Comotion d'Appel et de l'Ordre des Advocats, 1886, p. 90-138 e 212-248. Sobre os relatórios apresentados por Portugal cf. p 126-129 e 234-236.

${ }^{19}$ GUILLAUME - Le Congrès Penitentiaire International de Stockholm, 15-26 de Agosto 1878. Comptes-rendus des séances. Stockholm. Bureau de la Commission Pénitentiaire Internationale, 1879.

${ }^{20}$ GUILLAUME - Actes du Congrès Pénitentiaire International de Saint-Pétersbourg, 1890. Saint-Pétersbourg: Bureau de la Commission d'Organization du Congrès, 1892.

${ }^{21}$ Actes du Congrès Penitentiaire International de Washinghton. Outubro 1910.

${ }^{22}$ Acte du Congrès International des Tribunaux des Mineurs. Paris, 1911. 
A partir de 1900 havia já um plano elaborado à escala europeia, para propor reformas legislativas e das instituições, promover o patronato e criar os tribunais de menores segundo o modelo americano ${ }^{23}$.

As elites burguesas do século XIX e os movimentos religiosos, católicos e protestantes, consagraram os internatos para crianças e jovens, separados dos adultos. Para o final do século, o perfil da filantropia adquire uma nova feição especializada, com médicos, juristas e pedagogos e, apoiados em fortes movimentos sociais, principalmente de mulheres, e da elite financeira, angariam força para reclamar, junto das instâncias legislativas e governamentais, a criação dos tribunais de menores. O primeiro foi criado em 1899, no estado de Illinois, nos Estados Unidos. Em 1905 foi revista a lei e em 1911 existiam tribunais de menores em 26 estados norte-americanos. Esta experiência serviu de modelo e a sua difusão permitiu ganhar adeptos em diversos países. Na primeira década do século XX havia já tribunais da infância a funcionar na Alemanha, Inglaterra, Nova Zelândia, Austrália e Canadá e reuniam esforços para a sua criação em França, Bélgica, na Rússia, Áustria, Suíça e Hungria ${ }^{24}$.

\section{A Protecção judicial e as Tutorias/Tribunais de Menores em Portugal}

A primeira lei da protecção à infância foi o decreto de 1 de Janeiro de 1911 que criou as comissões de protecção. Foram criadas em Lisboa e no Porto, em Janeiro e Fevereiro, respectivamente. Mas foi a lei de protecção à infância (LPI) de 14 de Junho de1911, que deu início à organização de um sistema judicial de protecção às crianças e jovens, pioneiro na Europa na implementação das novas ideias da criminologia.

Este processo acompanhou as vicissitudes quer internacionais quer nacionais. Por um lado, fez-se sentir a representação portuguesa nos congressos internacionais, acompanhando as preocupações e os debates em

${ }^{23}$ Cf. DUPONT-BOUCHAT, M. T and PIERRE, E. - Enfance et justice..., cit., p. 397.

${ }^{24}$ CASABIANCA, M. Pierre - Comunicação ao Primeiro Congresso Internacional dos Tribunais de menores. Paris, 29 de Junho 1911, p. 306-307. 
$\operatorname{voga}^{25} \mathrm{e}$, por outro, com a primeira guerra mundial, viu-se agravar o problema da infância ao mesmo tempo que se fizeram sentir restrições orçamentais, que criaram fortes constrangimentos ao desenvolvimento do sistema ${ }^{26}$.

O sistema português implementado pela LPI, sob forte impulso de padre António Oliveira e com o apoio do ministro da Justiça e dos Cultos Afonso Costa, criou as Tutorias em Lisboa e no Porto (1911 e 1912 respectivamente)

${ }^{25}$ Encontrámos participação de personalidades portuguesas nos debates internacionais: nos Congressos Penitenciários Internacionais, Ferreira-Deusdado foi delegado oficial ao Congresso de 1890 em São Petersburgo e relator e participante em discussões no Congresso de Paris em 1895. Foi também presidente de Honra ao III Congresso Internacional de Antropologia Criminal de Bruxelas. Em 1885 em Roma, esteve João Silva Mattos, advogado em Lisboa e em 1878, em Estocolmo, M. Soto Maior, ministro plenipotenciário e enviado extraordinário ao congresso. No século XX encontrámos uma forte presença portuguesa em alguns eventos. Em 1911 houve três congressos, dois dos quais sobre a questão dos menores, mas onde não estiveram portugueses. O terceiro foi o VII Congresso Internacional de Antropologia Criminal, em Heidelberg onde estiveram como delegados do governo Barbosa de Magalhães e Júlio de Matos. Em 1921, no Segundo Congresso Internacional de Protecção à Infância os juízes Abel Pereira do Vale e Pereira de Castro apresentaram relatórios da situação portuguesa. Em 1925, J. J. Henriques da Silva, advogado e cônsul português em Swansea, foi delegado do governo português ao IX Congresso Penitenciário Internacional realizado em Londres. José Beleza dos Santos foi considerado por Eduardo Correia "uma das coordenadas de ligação do nosso país com o mundo culto". Foi chefe da delegação portuguesa aos Congressos Penais e Penitenciários Internacionais de Londres, Praga, Berlim e Haia, ao I Congresso das Nações Unidas de Genebra, entre outros. No II Congresso Internacional de Criminologia em 1950, realizado em Paris-Sorbone, estiveram os médicos psiquiatras Dr Baía Júnior, director Hospital Conde Ferreira; Fernandes H J. de Barahona, Professor de psiquiatria na Faculdade de Medicina de Lisboa; Marcelo Bastos de Barros, assistente da Faculdade de Medicina, médico no Conde Ferreira, assistente estrangeiro na Faculdade Medicina Paris; Óscar Teixeira de Bastos, médico chefe e auxiliar da direcção do Instituto de Medicina Legal, professor da polícia científica do curso Superior de Medicina Legal de Lisboa, encarregado do curso técnico de polícia e da Direcção da Polícia Judiciária de Lisboa, delegado do governo português; Dr. Correia de Oliveira, professor de psiquiatria da Faculdade Medicina da Universidade de Coimbra, representante da Clínica Psiquiátrica de Coimbra; Dr. Luís Augusto Duarte Santos, médico legista e psiquiatra, encarregado do curso da Faculdade de Medicina da Universidade de Coimbra e o Dr. Luís Vasco Navarro Soeiro médico psiquiatra do Hospital Júlio de Matos em Lisboa. Esteve também o Professor Doutor José Beleza dos Santos professor de Direito Penal da Faculdade de Direito da Universidade de Coimbra e delegado da Associação Internacional de Direito Penal. Relativamente aos congressos estas são apenas referências. Muito mais há para pesquisar e divulgar sobre as visitas e viagens de estudo realizadas por ordem dos governos, das traduções das obras de autores portugueses e de autores estrangeiros para português.

${ }^{26}$ Cf. OLIVEIRA, Augusto de - Movimento da Criminalidade em Portugal. Comunicação feita ao Congresso das Ciências da População, a convite da Comissão dos Centenários, em Setembro de 1940. Boletim Oficial do Ministério da Justiça. Ano I,(1940), p. 106. 
e, portanto, as condições para o desenvolvimento de "um processo de therapeutica moral, de hygiene preventiva contra o crime, antes do crime, e de hygiene curativa contra o crime consummado, de maneira a evitar a sua repetição" 27 , que permitiu a avaliação diagnóstica para determinação de medidas individualizadas de prevenção criminal e sua execução, de acordo com os novos preceitos legais. O resto do país teve de aguardar pela lei de 1925, que regulamentou a expansão do sistema, concluída apenas no Estado Novo ${ }^{28}$. Nas colónias portuguesas, o regime jurídico para menores foi estabelecido apenas em 1956, pelo decreto-lei n. ${ }^{\text {o } 40703, ~ d e ~} 26$ de Julho, para "tornar extensivas ao ultramar, pura e simplesmente, as disposições que na metrópole integram o regime jurídico de menores, com base no Código Civil, que está em vigor em todo o território nacional”, bem como "centralizar a política e descentralizar a administração" de forma a permitir a adequação dos procedimentos aos indígenas ${ }^{29}$.

O primeiro tribunal de menores foi criado em Lisboa com a designação de Tutoria da Infância. A publicação do estatuto judiciário de 1944 alterou a sua designação para Tribunal de Menores ${ }^{30}$ e em 1977 a Lei n. ${ }^{\circ}$ 82/77, introduziu profundas alterações à organização dos tribunais judiciais, levando à divisão entre tribunais de menores e tribunais de família.

A opção inicial pela designação Tutoria da Infância pretendia evitar o estigma gerado pelo tribunal, instituição de vocação punitiva, bem como funcionar com proximidade aos jovens, para prevenir e curar os problemas, mais do que condenar e sancionar. Na introdução à LPI define-se como "um tribunal collectivo especial, essencialmente de equidade, que se destina a defender ou proteger as crianças em perigo moral, desamparadas ou

${ }^{27}$ Diário do Governo n. ${ }^{\circ}$ 137, Lei de 14 de Junho de 1911. Introdução da LPI.

${ }^{28}$ Em 1931 havia 157 tutorias, três centrais, em Lisboa, Porto e Coimbra e as restantes comarcãs. Relativamente à rede institucional de suporte às decisões do tribunal, todos os refúgios e institutos de reforma ou correcção para raparigas foram criados a partir de 1927. Os institutos para rapazes, com excepção dos refúgios e do Instituto da Guarda, datam de finais do século XIX ou princípios do século XX. Cf. Relatório apresentado ao X Sessão da Associação, Internacional de Protecção à Infância. Miscelânea. Lisboa, 1931.

${ }^{29}$ No artigo $1^{\text {o }}$, único ficou estabelecido que os tribunais de menores funcionavam nos de comarca ou municipais. Não sendo objecto deste artigo, vale deixar nota sobre a regulamentação diferenciada para os jovens indígenas e não indígenas, quer em matéria de processo quer nos internatos, para cumprir medidas.

${ }^{30}$ Decreto-Lei n. ${ }^{\circ} 33547$ de 23 de Fevereiro de 1944 , artigo $8^{\circ}$ e $70^{\circ}$ a $72^{\circ}$. 
delinquentes, sob a divisa: educação e trabalho. Este tribunal julga pela sua consciência, como um bom pae de família, no amor pela verdade e justiça, e sempre no interesse das crianças". No julgamento deveria prevalecer o critério de necessidade de "despertar a criança para o cumprimento do bem (...) lavando-lhe a alma das sujidades, dos detrictos em que nasceu e se desenvolveu, e mostrando-lhe a lua clara da verdade, os ensinamentos rehabilitadores da justiça". Estes procedimentos constituíam na época novas formas de direito penal. "Para que a therapeutica estrictamente preventiva produzisse resultados apreciáveis, teve o presente decreto de procurar formas novas de direito civil". Assim, definiu as causas de inibição do poder paternal e simplificou e abreviou o processo.

As restrições orçamentais que se viviam na República aconselharam a dar início ao sistema, a título experimental, com a criação da Tutoria de Lisboa e para julgar apenas as causas relativas às crianças maltratadas, desamparadas e delinquentes. Fixou-se o número e categoria do pessoal do Depósito de Menores, os seus vencimentos e demais despesas, de entre a "verba de 10:000\$00 réis" que o decreto de 1 de Janeiro já havia estipulado. Pedia-se também o aumento dos vencimentos do quadro de pessoal da correcção de Caxias $^{31}$.

\subsection{As instituições judiciais da protecção}

As instituições que marcaram o arranque do sistema foram a Tutoria da Infância, o Refúgio da Tutoria Central de Lisboa e a Escola Central de Reforma de Lisboa. A Tutoria era composta por um juiz de direito, seu presidente e dois vogais com o título de juízes adjuntos, médicos, advogados ou professores, nomeados pelo presidente e escolhidos de entre homens bons ${ }^{32}$. Funcionavam também com o delegado da comarca, os agentes do Ministério

31 "Esse aumento fica ao cuidado da Assembleia Constituinte, que, olhando às circunstancias da nossa vida económica nacional, não deixará de olhar também aos dispêndios de energia a que corresponde o aproveitamento dos menores confiados ao trabalho, à iniciativa do respectivo pessoal, e ao dever de estimular os que não se pouparam a canseiras a fim de transformar numa casa modelo o que há alguns anos era considerado o Inferno das crianças". Preâmbulo da LPI.

${ }^{32}$ Artigo $5^{\circ}$ e seguintes da LPI. 
Público e os delegados de vigilância ${ }^{33}$. O Refúgio e a Escola Central de Reforma eram instituições da Federação Nacional dos Amigos e Defensores das Crianças e eram dotadas com pessoal administrativo, de vigilância, professores e preceptores para fazer funcionar o sistema socioeducativo do internato e dos serviços domésticos para a organização do quotidiano da vida interna. O Refúgio tinha ainda um médico a dirigir o posto antropométrico, uma enfermeira e, como pessoal auxiliar, professores de trabalhos manuais, de canto coral, de ginástica e instrução militar ${ }^{34}$. A Escola de Reforma estava dotada de mestres para fazer formação para profissões industriais (marcenaria, trabalhos em talha, serralharia mecânica ou artística, litografia, tipografia, alfaiataria e sapataria) e agrícolas (horticultura, pomologia e jardinagem $)^{35}$.

A par com a Tutoria, a LPI criou a Federação Nacional dos Amigos e Defensores das Crianças (artigo $112^{\circ}$ a $131^{\circ}$ ), que definiu como a "união jurídica, moral e facultativa de várias instituições, quer officiais quer particulares, de propaganda, educação e patronato, que deverão formar um verdadeiro systema de hygiene moral e social". Era superintendida pela Junta Superior ${ }^{36}$ e contava na sua composição com o Director Geral da Assistência Pública. A estrutura organizacional, previa a descentralização dos serviços. Havia três circunscrições (norte, centro e sul) e, em cada, uma junta central com uma delegação em cada comarca, a junta comarcã, e esta com uma subdelegação em cada freguesia, a junta paroquial. Pertenciam à Federação instituições de propaganda, de educação preventiva, de educação reformadora ou correccional e de patronato. Qualquer instituição do ministério da Justiça criada ou reformada pela LPI era por direito, uma instituição federada. Já os internatos de outro ministério, destinados à

${ }^{33}$ Segundo o artigo $16^{\circ}$ da LPI, os delegados de vigilância formavam um corpo de polícia especial, que tinham por função: fazer os inquéritos aos pais ou tutor; deter ou prender os menor ou os seus pais ou tutores e levá-los à presença do juiz; vigiar os menores que lhes forem indicados e desempenhar as suas funções conforme o estatuto.

${ }^{34}$ Artigos n. ${ }^{\circ} 138^{\circ}, 139^{\circ}, 141^{\circ}$ e $142^{\circ}$.

${ }^{35}$ Artigos n. ${ }^{\circ} 161^{\circ}, 162^{\circ}, 176$ e $177^{\circ}$ da LPI.

${ }^{36}$ A presidência da Junta Superior foi entregue, primeiro, ao Presidente da Comissão de Protecção, depois passou para o Ministro da Justiça e, no Decreto-lei 10:767 de 1925, para o Inspector-Geral dos Serviços Jurisdicionais de Menores, primeiro António Augusto de Oliveira e depois Eurico Serra Simões. 
educação gratuita de menores abandonados, pobres ou maltratados, podiam ser nela incorporados, desde que os seus estatutos ou regulamentos fossem aprovados pelo ministro da Justiça. O patronato era constituído por todas as associações de beneficência destinadas a policiar, vigiar e controlar os jovens, quer para evitar desvios no seu comportamento quer para os apoiar à saída dos internatos. Devia também auxiliar a acção da Tutoria e dos delegados de vigilância.

O decreto 10:767 de 15 de Maio de 1925, alterou a sua designação para Federação Nacional da Instituições de Protecção à Infância (FNIPI), que passou a representar as instituições de protecção à infância na "Association International de la Protection de l'Enfance", sediada em Bruxelas. A Federação tornou-se uma instituição pivot na relação com as associações nacionais, internacionais, de serviço social e da jurisdição de menores. A partir de 1952 integrou o Comité Executivo da União Internacional de Protecção à Infância (UIPI) e de 1955 criou a Revista Infância e Juventude, órgão da Federação, que se dedicou ao estudo dos temas relativos aos serviços e a difusão de ideias sobre o direito de menores.

Os recursos disponíveis para a protecção à infância ficaram por esta via com maior potencial de articulação entre os serviços públicos e privados e entre os diferentes sectores da justiça, saúde e educação relativos às políticas para a família e para os jovens. Em 1931, a rede de estabelecimentos do ministério da Justiça contava com três refúgios, cada um com secções masculina e feminina, três colónias correccionais, sendo duas masculinas, 5 reformatórios, sendo um para raparigas e mais dois em projecto ${ }^{37}$. A Direcção Geral de Assistência contava com sete internatos federados ${ }^{38}$, o ministério da Guerra com três ${ }^{39}$, a Misericórdia de Lisboa com nove e os corpos administrativos e instituições privadas no país, incluindo ilhas,

${ }^{37}$ Um deles veio a ser o Instituto Navarro Paiva, para "anormais" e o outro, o reformatório marinho que, cremos, não foi nunca activado. Relatório apresentado à X Secção da Associação Internacional de Protecção à Infância. Miscelânea. Lisboa, 1931.

${ }^{38}$ Casa Pia, Asilo 28 de Maio, Asilo Nuno Álvares, Asilo Maria Pia, Escola Profissional Santa Clara e Asilo José de Magalhães. OLIVEIRA, Augusto - Les Services de Jurisdiction et de Tutelle des Mineurs au Portugal. Miscelânea. Lisboa, 1931, p. 24.

${ }^{39}$ Colégio Militar, Instituto Feminino de Educação e Trabalho e Instituto dos Pupilos do Exército. Cf. OLIVEIRA, Augusto - Les Services de ... cit., p. 24. 
cento e dezanove internatos ${ }^{40}$. Pudemos contar um total de 138 instituições de protecção, assistência e educação, com vocação para acolher crianças em perigo ou desamparadas. Parece ainda interessante registar o papel que vieram a desempenhar na educação, saúde e luta contra a pobreza infantil, os lactários, as cantinas e os dispensários, instituições a que a República deu fôlego e que proliferaram pela cidade de Lisboa.

\section{A Situação da Criança e a expansão do sistema. A criação da Tutoria da Infância de Coimbra}

A LPI assegurou melhorias no estatuto da criança e dos jovens, abriu-lhes espaço no mundo dos direitos. Contudo, a sua condição efectiva viu algumas dificuldades de promoção. Primeiro porque demorou quase duas décadas a expandir-se ao país, segundo porque se mostrou insuficiente para responder cabalmente às necessidades da "criança portuguesa" e terceiro, pelo tipo de selectividade que impôs no acesso à protecção. Mesmo onde já funcionavam as suas instituições, a regularização da situação das crianças e jovens presos, teve de aguardar ainda algum tempo. Não tardaram vozes de protesto nos discursos da Assembleia Nacional Constituinte. Ainda não tinha passado um mês sobre a publicação da LPI, e já se reclamava contra a situação de 54 crianças presas no Limoeiro, exigindo-se que, pelo menos, não fossem detidas na casa dos entrados, em promiscuidade com todos os criminosos $^{41}$. Bernardino Machado afirmava a urgência de passar as crianças para as casas de correcção. Chamou à discussão a falta de dotação para o acolhimento dos jovens e a necessidade de fazer um crédito extraordinário para dotar as casas de correcção dos meios indispensáveis ao cumprimento das suas obrigações. Afirmava "os menores podem ser abandonados pelas famílias, não o podem ser pelos poderes públicos e, sobretudo, o que não se pode consentir é a promiscuidade dessas crianças com os criminosos". Havia também crianças esquecidas na prisão, outras que tinham transitado

\footnotetext{
${ }^{40}$ OLIVEIRA, Augusto - Les Services de ... cit., p. 24-27

${ }^{41}$ Denúncias feitas por Botto Machado e José Cordeiro na 19a sessão de 12 de Julho de 1911, da Assembleia Nacional Constituinte.
} 
de uma casa de correcção para a prisão por mau comportamento ${ }^{42}$, etc. Um sem número de situações sinalizadas na capital chamava a atenção para a urgência de agilizar o sistema para assumir as funções que lhe competiam.

As crianças "anormais" de todo o país viveram tempos difíceis e parcos em soluções adequadas. Dirigida por Victor Fontes, existia no Instituto Aurélio da Costa Ferreira uma escola de reeducação de menores "anormais", criada em 1915. O Instituto Médico-Pedagógico, criado em 1925 e dirigido pela condessa de Rilvas destinava-se ao tratamento especializado de 40 raparigas "anormais" (físicas e psíquicas). Em 1930 foi criado pelo decreto n. ${ }^{\circ} 18375$ de 17 de Maio o Instituto Navarro de Paiva, que abriu portas a um serviço de estudo e tratamento médico-psicológico dos menores delinquentes, indisciplinados ou inadaptados com deficiências ou irregularidades mentais, em 1956, anexo ao Centro de Observação de Lisboa. Fora de Lisboa não havia respostas socioeducativas para jovens com dificuldades.

Outro problema de grande dimensão nacional era a pobreza infantil. Várias acções foram desenvolvidas para o seu combate, mas, como dizia Fátima Caldeira, "A pobreza falou sempre mais alto"43. Em Coimbra, esta questão impunha-se, reunindo a atenção tanto dos parlamentares como dos jornais locais. Em 1931 havia na região sete internatos, para acolhimento de rapazes e raparigas ${ }^{44}$, mas eram frequentes as notícias das dificuldades vividas para manter o seu funcionamento quotidiano. Assim aconteceu em Coimbra com a Misericórdia e com o Asilo da Infância Desvalida, por exemplo. Em 1920 o deputado Alves dos Santos propunha à Câmara de Deputados o depósito de 2000\$00 para a Misericórdia de Coimbra, pois, não obstante os seus bons serviços a rapazes e raparigas em matéria de assistência e educação profissional e técnica, "este estabelecimento

${ }^{42}$ Denúncias de Botto Machado e Relato da história por Eusébio Leão, na $19^{\mathrm{a}}$ sessão de 12 de Julho de 1911 da Assembleia Nacional Constituinte.

${ }^{43}$ CALDEIRA, Maria de Fátima - Assistência infantil em Lisboa na $1{ }^{a}$ República. Casal de Cambra: Caleidoscópio, 2004.

${ }^{44}$ Asilo da Infância Desvalida da Misericórdia de Cantanhede, Colégio dos Órfãos e Órfãs de S. Caetano da Misericórdia de Coimbra, Asilo da Infância Desvalida em Coimbra, Escola Profissional Agrícola em Semide, A "Obra da Figueira" (Asilo para crianças desvalidas do concelho da Figueira da Foz), Preventório de Penacova e o "Ninho dos Pequenitos" em Coimbra. 
luta com profundas dificuldades (...) já tomou a decisão de licenciar"45. Em 1926 um "grupo de senhoras da melhor sociedade conimbricense" decidiu fazer uma quermesse em favor do Asilo da Infância Desvalida para ajudar o professor Elísio de Moura e sua esposa na manutenção da obra. Com um rendimento suficiente para alimentar apenas seis crianças, o Asilo abrigava 32 meninas de famílias pobres ${ }^{46}$. Paulo Menano lembrava em 1922 o problema das crianças que viviam ao abandono na rua, a necessidade de evitar o desenvolvimento da prostituição das raparigas, a depravação dos costumes e a vadiagem dos rapazes.

Assim, a reclamação pela criação da Tutoria da Infância e respectivo Refúgio em Coimbra surgia pela necessidade de garantir assistência, mais do que responder à criminalidade juvenil. Segundo Caetano Gonçalves, Coimbra era uma cidade pequena, pouco populosa e sem grande desenvolvimento industrial, sem grandes índices de criminalidade juvenil ou mesmo adulta ${ }^{47}$ e os processos dos/das menores eram julgados nos tribunais comuns e as sentenças cumpridas na prisão. Foi por exemplo o caso da jovem Emília ${ }^{48}$ que em 1914, quando tinha 12 anos de idade, foi arguida de um processo de polícia correccional pelo crime de ofensas corporais, que cometeu quando era criada de servir em casa de um casal residente em Coimbra e que, a brincar com uma pressão de ar que era do patrão, feriu o seu filho, rapaz de 11 anos, que ficou cego do olho esquerdo. Foi julgada no Tribunal de Comarca de Coimbra, pelo juiz José Cupertino d'Oliveira Pires e António Dias, delegado do procurador na comarca, e foi presa ${ }^{49}$.

${ }^{45}$ Sessão de 30 de Junho de 1920.

${ }^{46}$ O Despertar de 26 de Junho de 1926.

${ }^{47}$ GONÇALVES, Caetano - Os serviços de protecção a menores desamparados e delinquentes em Portugal. Boletim do Instituto de Criminologia. I e II. (1922-1923).

${ }^{48}$ Não facultamos identificação da jovem, a fim de garantir o sigilo sobre a pessoa e/ou seus descendentes.

49 Arquivo da Universidade de Coimbra, depósito VI - Secção I, estante 1, tabela 4 e $\mathrm{n}^{\circ} 5$, maço $17, \mathrm{n}^{\circ}{ }^{\mathrm{7}} 762$. A história é reconstruída a partir dos documentos que constam do processo, como acusação, auto de notícia, inquirições e outros. Foi autor do processo o Ministério Público. 


\subsection{A Criação da Tutoria Central da Infância de Coimbra e o Refúgio anexo ${ }^{50}$}

A Tutoria Central da Infância de Coimbra e o Refúgio anexo, que foram criados pela LPI de 1911, tiveram de esperar até 1927 para começar a funcionar como Tutoria Central e até 1935 para o exercício pleno das suas funções.

As primeiras leis relativas à sua instalação são de 1914 (decreto n. ${ }^{0} 722$ de 4 de Agosto e n. ${ }^{\circ} 897$ de 29 de Setembro) e definem o quadro e despesas de pessoal e alimentação, vestuário e calçado dos menores ${ }^{51}$ para o funcionamento dos serviços, bem como o salário do juiz de direito que for nomeado. O decreto n. ${ }^{\circ} 2955$ de 25 de Janeiro de 1917 estabeleceu a cerca e o Colégio das Ursulinas (actual Hospital Militar) para a instalação da Tutoria e Refúgio, mas tal não veio a concretizar-se. O início do processo de criação efectiva dos serviços teve origem apenas no projecto de lei n..$^{\circ}$ 96-F, apresentado à Câmara de Deputados por Pedro Pita em 12 de Maio de 1922, com a proposta de cedência ao Ministério da Justiça do presbitério de Santo António dos Olivais. Aprovado pelas comissões das finanças e da legislação criminal, foi publicado a 9 de Janeiro de 1923 na Câmara de Deputados e apresentado ao Senado em proposta de lei n. ${ }^{0} 350$. Em 8 de Janeiro de 1924 é publicada a lei n. ${ }^{\circ} 1523$ do ministério das Finanças que autoriza finalmente a cedência ao ministério da Justiça e dos Cultos do presbitério de Santo António dos Olivais, para instalação da Tutoria Central da Infância de Coimbra, permitindo dar início a todo um processo ainda longo, para construção da Tutoria, do Refúgio anexo, do posto policial e das obras necessárias ao aproveitamento agrícola da quinta.

A Tutoria e Refúgio, foram construídos em zona peri-urbana de Coimbra, em confronto a Oeste com a igreja de Santo António dos Olivais. Em Abril de 1925 deu-se início à construção do pavilhão masculino e às obras de adaptação do edifício destinado ao tribunal. As obras do pavilhão feminino só

${ }^{50}$ A história da Tutoria da Infância de Coimbra e do seu Refúgio anexo, bem como da população que o povoou, está ainda em construção, pelo que, o que agora apresentamos não é mais do que uma breve e primeira abordagem a público, de uma outra história, mais completa e complexa.

${ }^{51}$ Previa-se no decreto . $^{0} 722$ a abertura do Refúgio anexo à Tutoria apenas para rapazes. 
iniciaram em 1927 e as do lar de semi-internato em 1930. Em 1933 estavam realizadas as obras e instalados os equipamentos para o seu funcionamento, mas só em 1935 o posto policial e o posto de observação estavam concluídos.

O investimento financeiro e a nomeação da equipa que pôs em funcionamento este complexo judicial de protecção à infância em Coimbra, dão conta do empenho do Estado nesta obra. O juiz presidente da Tutoria da Infância foi José Beleza dos Santos, professor da cadeira de Direito Penal na Faculdade de Direito da Universidade de Coimbra e os juízes adjuntos Fernando Duarte Silva de Almeida e Maximino José Novais Correia, professores da Faculdade de Medicina. O Director do Refúgio e presidente da comissão instaladora da Tutoria e Refúgio foi João Cardoso Moniz Bacelar que contou com Maximino José Novais Correia como médico do Refúgio. O primeiro professor preceptor nomeado foi Manuel Barbosa, licenciado em História pela Universidade de Coimbra e o professor de trabalhos manuais, Álvaro Viana de Lemos, eminente personalidade da pedagogia portuguesa, pelo contributo para a introdução da discussão e dos métodos da Escola Nova em Portugal.

Em 8 de Abril de 1927 entraram os três primeiros jovens, à ordem da Polícia de Segurança Pública de Coimbra, por vadiagem. Saíram do Refúgio em Julho de 1929, dois em liberdade definitiva e um, em liberdade vigiada. Vejamos quem foi o primeiro entrado/julgado, com um olhar filtrado pelo pensamento médico, pedagógico, sanitário, social e moral da época.

O entrado n. ${ }^{\circ} 1$, Manuel, era filho de um guarda-republicano e de uma alienada, que "indoideceu no parto". Aos 3 anos ficou abandonado sem qualquer educação (dos pais, da escola ou da oficina) e aos 13 foi preso por ter furtado dinheiro a um tio. Depois disso viveu uns tempos em lares. Apesar de ter tido sarampo e uma pneumonia, o seu crescimento foi normal, tal como o desenvolvimento da dentição, marcha e linguagem. Do exame antropométrico não ficaram registos de anomalias ou deformidades e o exame médico indicava tratar-se de um jovem com bom desenvolvimento do esqueleto e dos pulmões e normal desenvolvimento dos restantes órgãos e sistema nervoso. Quanto à observação psicológica, registou-se que era um rapaz bem-humorado, bem comportado, aplicado no trabalho, sem maus hábitos, púbere, mas ainda sem prática de relações sexuais. Os registos do preceptor indicavam tratar-se de um rapaz com "bom carácter mas pouco 
trabalhador e mole". Esta história é semelhante às muitas outras que se lhe seguiram.

As raparigas entraram apenas a partir de 1928, mas sempre em menor número do que os rapazes. Misto até 1995, o Refúgio/Centro de Observação viu entrar 983 jovens de ambos os sexos até $1940^{52}$ e pelo menos 1095 , dos quais 896 foram rapazes, entre 1958 e $1978^{53}$.

Os números pouco nos dizem acerca da dimensão do fenómeno da infância em perigo, desamparada ou delinquente em Coimbra, primeiro porque respeitam apenas aos processos sobreviventes às condições do arquivo e, segundo, porque a selectividade do sistema era grande. Mesmo se infractor à lei penal, a sua história confundia-se quase sempre com uma história de privação (material, educativa e/ou afectiva), razão pela qual encontrámos muito poucos registos de jovens que não eram designados de pobres. Durante quase todo o século XX, o acesso ao sistema de protecção judicial era mais ou menos arbitrário. Depois de entrado, o jovem era sujeito a um processo de observação diagnóstica e prognóstica, médica, pedagógica e social, seguindo procedimentos sob orientação internacional que ficaram legalmente estabelecidos nas sucessivas leis (da LPI de 1925 à OTM de 1978) e que pretendiam garantir a aplicação de medidas individualizadas de prevenção criminal. O juízo elaborado criava o "criminoso antes do crime" pela identificação do grau de perigosidade de cada jovem, ao mesmo tempo que a medida aplicada confundia as motivações penais ou sociais da política de protecção de menores. Na prática, a relação estabelecida entre prevenção e protecção, como garantia de ordem e paz social, foi uma fórmula coerente para a garantia da defesa social, mas em rota de colisão com a garantia dos direitos e da cidadania infantil, particularmente desta infância pobre, que sai duplamente penalizada, sujeita a um processo de clientelização, não apenas estigmatizante, mas também criminalizador da sua condição social de desfavorecida.

${ }^{52}$ Dados apresentados na crónica de Padre Milciades - Da antiga Tutoria ao Centro de Observação Anexo ao Tribunal Tutelar Central de Menores de Coimbra. Diário de Coimbra de 23 de Junho de 1975.

${ }^{53}$ Relativo a este período existem (sobreviveram) 1095 boletins de observação de Jovens que ali passaram para observação e estão nos Arquivos do Centro Educativo dos Olivais.

${ }^{54}$ FOUCAULT, Michel - O nascimento da clínica. Rio de Janeiro: Editora Forense Universitária, 1998. 